\title{
Mesopause temperature perturbations caused by infrasonic waves as a potential indicator for the detection of tsunamis and other geo-hazards
}

\author{
M. Bittner, K. Höppner, C. Pilger, and C. Schmidt \\ German Remote Sensing Data Center (DFD), German Aerospace Center (DLR), Oberpfaffenhofen, Germany \\ Received: 31 March 2010 - Revised: 31 May 2010 - Accepted: 6 June 2010 - Published: 2 July 2010
}

\begin{abstract}
Many geo-hazards such as earthquakes, tsunamis, volcanic eruptions, severe weather, etc., produce acoustic waves with sub-audible frequency, so called infrasound. This sound propagates from the surface to the middle and upper atmosphere causing pressure and temperature perturbations. Temperature fluctuations connected with the above mentioned events usually are very weak at the surface, but the amplitude increases with height because of the exponential decrease of atmospheric pressure with increasing altitude. At the mesopause region (80-100 km height) signal amplitudes are about two to three orders of magnitude larger than on the ground.

The GRIPS (GRound-based Infrared P-branch Spectrometer) measurement system operated by the German Remote Sensing Data Center of the German Aerospace Center (DLRDFD) derives temperatures of the mesopause region by observing hydroxyl $(\mathrm{OH})$ airglow emissions in the near infrared atmospheric emission spectrum originating from a thin layer at approximately $87 \mathrm{~km}$ height.

The GRIPS instrument is in principle suited for the detection of infrasonic signals generated by e.g. tsunamis and other geo-hazards. This is due to the fact that the infrasound caused by such events should induce observable shortperiod fluctuations in the $\mathrm{OH}$ airglow temperatures. First results obtained during a field campaign performed at the Environmental Research Station "Schneefernerhaus", Zugspitze $\left(47.4^{\circ} \mathrm{N}, 11.0^{\circ} \mathrm{E}\right)$ from October to December 2008 are presented regarding potential sources of meteorological and orographical origin.
\end{abstract}

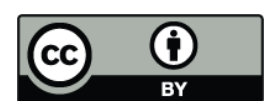

Correspondence to: M. Bittner (michael.bittner@dlr.de)
An adequate distinction of the overlapping infrasonic signatures caused by different infrasound sources in the $\mathrm{OH}$ temperature record is needed for the ascription to the proper source. The approach presented here could form a contribution to a hazard monitoring and early warning system.

\section{Introduction}

Infrasound is generated by a wide variety of natural sources as e.g. earthquakes, volcanic eruptions or severe weather, but also by man-made sources such as explosions, aircrafts or industrial activities (see Gossard and Hooke, 1975; Blanc, 1985; Campus, 2004 for an overview on infrasonic sources). Because infrasound travels over large distances and is subject to only low atmospheric attenuation, in comparison to audible sound (Sutherland and Bass, 2004), it can be measured over distances of many hundreds and even thousands of kilometers. At surface level, pressure-based infrasound measurements using ground-based microbarometers and infrasonic arrays are used for e.g. monitoring nuclear weapon tests in support of the comprehensive nuclear test ban treaty (CTBT, see PrepCom, 1997), as well as for the detection of meteorological or volcanic activities (see e.g. Bowman and Bedard, 1971; Ripepe and Marchetti, 2002) and several other natural phenomena (see e.g. Evers and Haak, 2001; Mutschlecner and Whitacker, 2005; Johnson et al., 2006). Investigations related to tsunami induced infrasound have recently been performed as part of the 2004 Sumatra earthquake and its associated tsunami (see Le Pichon et al., 2005; Garces et al., 2005).

However, the detection of infrasound by means of temperature measurements in the upper mesosphere (instead of surface pressure measurements) is a new approach to infrasound detection and is the subject of this paper. 


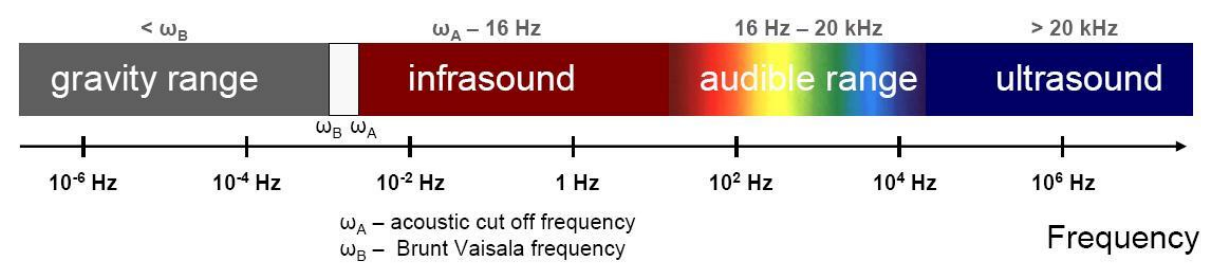

Fig. 1. The frequency range of infrasound embedded between the gravity wave and the audible range. It corresponds to periods of $0.05 \mathrm{~s}$ up to $5 \mathrm{~min}$.

Infrasonic waves are sound waves with frequencies below $16 \mathrm{~Hz}$, which is in the sub-audible range. Infrasound is on the other hand limited by the acoustic cut-off frequency at about $0.003 \mathrm{~Hz}$, which separates sound from gravity waves. This frequency range corresponds to signal periods of $0.05 \mathrm{~s}$ up to 5 min (see Fig. 1).

Sound waves are longitudinal waves because wave disturbances travel parallel to the direction of wave propagation. They occur in the atmosphere when a periodic vibration causes alternating adiabatic compression and expansion of air. In each wave induced compression cycle of the gas there will be a temperature increase $T^{\prime}$ (see Liszka, 1977):

$T^{\prime}=\frac{u}{c}(\gamma-1) T$

where $c$ is the sound velocity, $u$ the particle velocity, $\gamma$ the specific heat ratio and $T$ the ambient temperature. Assuming an infrasonic source signal of a certain initial pressure amplitude, one can calculate the expected particle velocities and resulting temperature perturbations occurring in a specified layer of the atmosphere as e.g. in the mesopause airglow layer at $\sim 87 \mathrm{~km}$ height (see Sect. 2.2). The effects of infrasound on the middle and upper atmosphere in terms of temperature fluctuations have been quantified by e.g. Schubert et al. (2005), Krasnov et al. (2007) or Pilger and Bittner (2009).

Neither pressure nor temperature fluctuations in the atmosphere can be easily measured above the stratosphere. Aircrafts and balloons do not reach such altitudes. Rocket measurements are sparse and expensive and satellite based measurements do not usually provide the spatial resolution needed for infrasound detection. However, a number of techniques have been developed during the past decades that allow indirect detection of the temperature in higher altitudes. One of them is the remote sensing of the airglow in the mesopause region ( $80-100 \mathrm{~km}$ altitude). The airglow is electromagnetic radiation emitted in the upper mesosphere in the visible and near infrared due to atomic and molecular excitations at these heights. One prominent airglow source is a rather narrow layer of excited hydroxyl $(\mathrm{OH})$ molecules from about $83-90 \mathrm{~km}$ height peaking around about $87 \mathrm{~km}$ (e.g. Baker and Stair, 1988). The excitation is caused by the exothermic reaction of ozone and atomic hydrogen (Bates and Nicolet, 1950; Meinel, 1950a).
The derivation of temperatures at this altitude from the measurement of the hydroxyl airglow spectra is a well established technique which is being routinely performed around the globe at many measurement stations (see e.g. Beig et al., 2003, and references therein) of which many have recently formed the Network for the Detection of Mesopause Change (NDMC; http://wdc.dlr.de/ndmc). These airglow derived temperatures have been used for example for studying planetary waves with periods from days to weeks (e.g. Sivjee et al., 1994; Espy et al., 1997; Takahashi et al., 2002; Buriti et al., 2005; Höppner and Bittner, 2007; López-González et al., 2009) as well as for investigating atmospheric gravity waves with periods of several hours down to about $8 \mathrm{~min}$ (e.g. Gavrilov et al., 2002; Reisin and Scheer, 2004).

Time series of $\mathrm{OH}$ temperatures occasionally show signatures of periods even below $5 \mathrm{~min}$ if the temporal resolution of the used instrument is sufficiently high. Possible sources of such small-scale signatures are infrasonic signals.

The German Remote Sensing Data Center (DLR-DFD) operates the GRIPS (GRound-based Infrared P-branch Spectrometer) instruments for the measurement of hydroxyl airglow intensities with high temporal resolution (Bittner et al., 2002). First tests for detecting specific infrasound signals were performed during a measurement campaign at the Environmental Research Station Schneefernerhaus (UFS, $47.4^{\circ} \mathrm{N}, 11.0^{\circ} \mathrm{E}$ ) at the Mountain Zugspitze in southern Germany during October-December 2008. The detection and identification of signals in the infrasound low frequency regime, most likely generated by meteorological activities and the Alpine orography, was achieved using a new detector technology which delivers the required high temporal resolution measurements.

Figure 2 shows the theoretical concept of our approach: a tsunami generates an infrasonic wave which travels from its ocean surface source through the atmosphere. Most of the wave energy is radiated nearly perpendicular to the ocean's surface into the upper atmosphere. When infrasound propagates upwards, its amplitude grows (due to the decreasing air density and the conservation of momentum) by up to about two to three orders of magnitude at the mesopause (about $90 \mathrm{~km}$ altitude). Infrasonic waves generated at the surface typically reach this region within about $5 \mathrm{~min}$. The pressure perturbations of an infrasonic signal correspond to temperature fluctuations in the atmosphere via ideal gas 


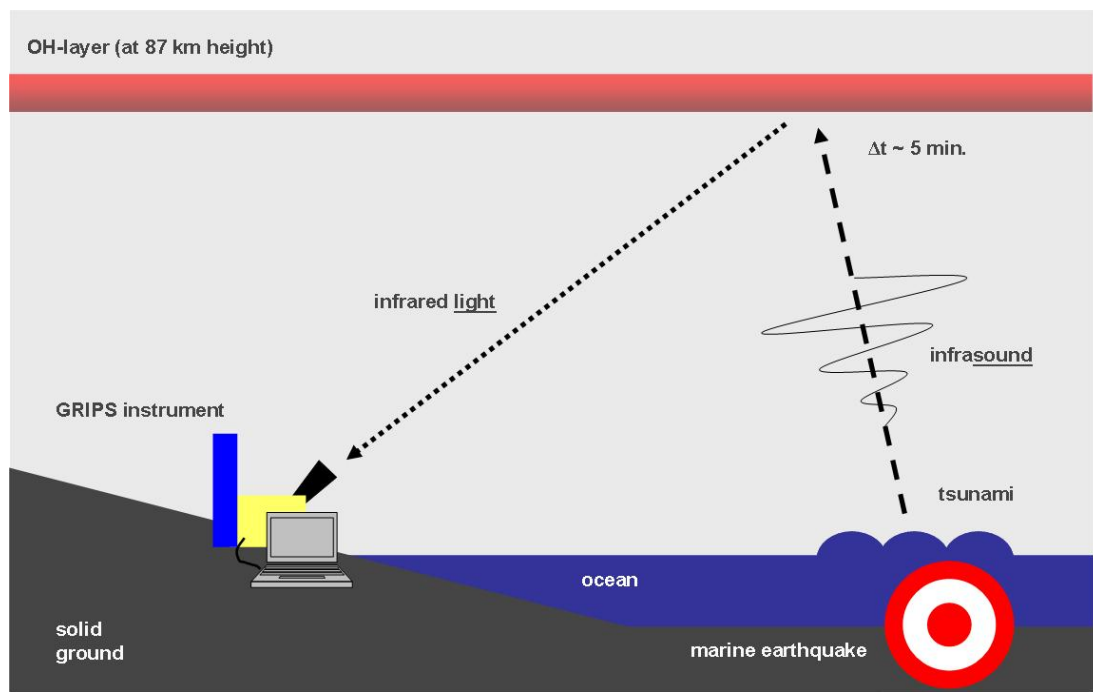

Fig. 2. Concept of infrasound generation and propagation, its impact on the mesospheric hydroxyl layer and the resulting radiation measured by the ground based infrared spectrometer GRIPS (see text for details).

law assumptions. These perturbations modulate the $\mathrm{OH}$ temperatures on their travel through the airglow layer in the mesopause region. Using the measurement technique of infrared spectroscopy with sufficient high temporal resolution in conjunction with a versatile signal classification algorithm, it should be possible to detect and identify the signals associated with geo-hazards such as a tsunami. If this can be reliably demonstrated then the measurement system could be deployed for the rapid detection of such hazards.

The study presented is part of the GITEWS (GermanIndonesian Tsunami Early Warning System) project (Rudloff et al., 2009).

The paper is organized as follows. The modeling of infrasound propagation, the quantification of infrasonic effects and first comments on signal parameters is presented in Sect. 2. The measurement principle as well as a description of the instrumentation is given in Sect. 3. In Sect. 4 preliminary results of infrasound induced temperature fluctuations recorded during a few weeks measurement period are presented.

\section{Modeling approach}

\subsection{Infrasound propagation modeling}

The propagation of infrasound from a surface source to the mesopause region and higher can be modeled with e.g. raytracing methods (see Jones et al., 1986; Drob et al., 2003; Pilger and Bittner, 2009). The ray-path calculations are performed using the Hamilton equations of motion and are solved numerically by use of the HARPA program (Hamiltonian Ray-Tracing Program for Acoustic Waves in the Atmosphere; Jones et al., 1986). HARPA is a commonly used and well established numerical code for 3-D infrasonic ray-tracing. Atmospheric background conditions such as the pressure-, temperature-, and wind-profiles are an integral part for the propagation calculations for infrasound. The HARPA code was modified by including climatologies for atmospheric background conditions (see below). The modified version is denoted as HARPA/DLR (Pilger and Bittner, 2009).

The climatology NRL-MSISE-00 (Naval Research Laboratories-Mass Spectrometer and Incoherent Scatter Radar; Picone et al., 2002) is used for the representation of atmospheric temperatures. For the modelling of wind fields the HWM-93 (Horizontal Wind Model; Hedin et al., 1996) was chosen. A further aspect of propagation modelling is the influence of signal attenuation. The influence of geometric spreading (weakening of a signal with range due to expansion) and atmospheric attenuation (damping due to thermal and molecular processes) is also considered in the improved HARPA/DLR program code.

The modifications include the attenuation processes of viscosity, thermal conductivity, diffusion and relaxation with height- and frequency-dependent formulae (see Sutherland and Bass, 2004). Further programming improvements for these calculations include height-dependent atmospheric composition and molecular mass, temperature-dependent collision numbers and a 5th-order polynomial approximation to the atmospheric pressure profile (instead of scale-height).

Figure 3 shows a typical propagation pattern of sound waves radiated from a point source on the ground. The initial inclination angles of sound rays are equally spaced from parallel to perpendicular radiation with respect to the ground. Obviously, the total amount of acoustic energy is transported upwards in the atmosphere, where it is either dissipated at thermospheric heights or reflected back to the ground. 


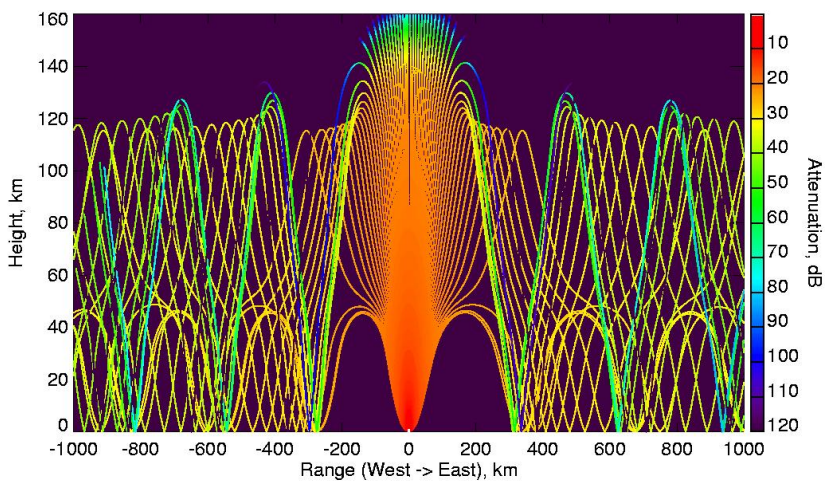

Fig. 3. A typical infrasound propagation pattern of a surface point source including acoustic loss due to atmospheric attenuation and geometric spreading, modelled with HARPA/DLR. The signal loss is coloured and given in the relative unit of decibel.

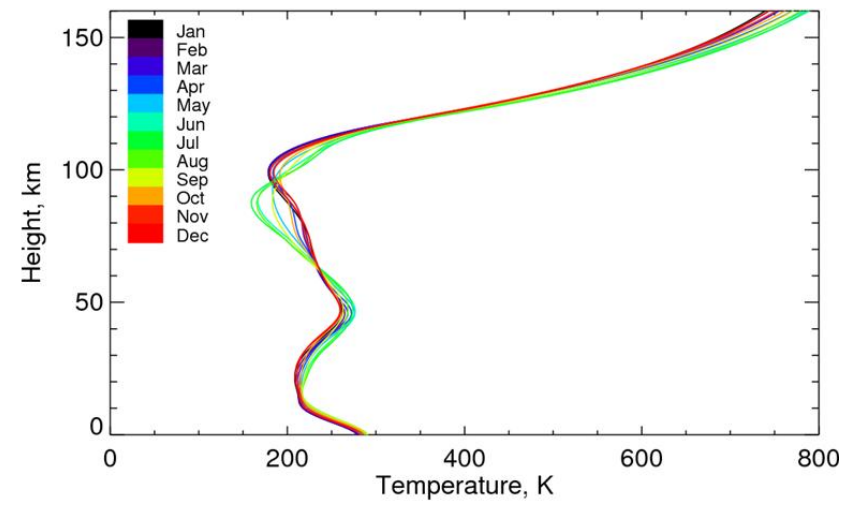

Fig. 4. MSISE-00 output for the monthly mean temperature profile at Munich, Germany $\left(48.1^{\circ} \mathrm{N}, 11.6^{\circ} \mathrm{E}\right)$. The strong positive temperature gradients in the stratosphere and lower thermosphere lead to acoustic ray reflections and surface returns (so-called "ducts"). There are also strong seasonal influences like the cold (warm) mesopause in summer (winter).

The so-called "ducting" of acoustics rays and their returns to the surface are predominantly caused by strong temperature gradients in the atmosphere. These gradients mainly appear in the stratosphere ("stratospheric duct") and the lower thermosphere ("thermospheric duct"), where the temperature strongly increases. The influences of horizontal wind on the propagation were found to be of secondary importance, but not negligible in the context of background modelling.

Figures 4 and 5 show model outputs of MSISE-00 of monthly means of temperature and zonal wind fields calculated, for example, for Munich, Germany $\left(48.1^{\circ} \mathrm{N}, 11.6^{\circ} \mathrm{E}\right)$. Seasonal structures in the temperature and the zonal wind have a significant effect on the wave propagation in the atmosphere. The semi-annual wind reversal in the stratosphere is well represented by the HWM-93 model. It has been mentioned above that realistic temperature and wind data are re-

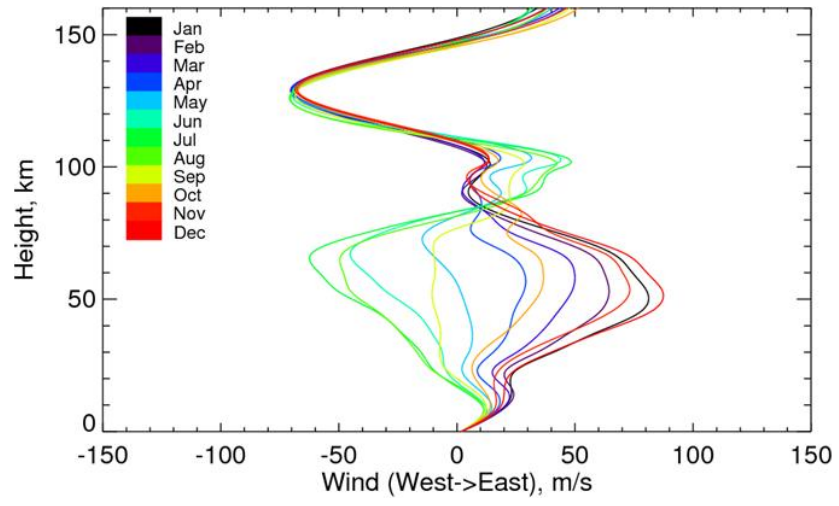

Fig. 5. HWM-93 output for monthly mean zonal wind profiles at Munich, Germany $\left(48.1^{\circ} \mathrm{N}, 11.6^{\circ} \mathrm{E}\right)$. The changing direction of the stratospheric wind jet from winter to summer leads especially to horizontal variations in the propagation pattern of infrasound.

quired to allow for precise infrasound propagation prediction. Smaller scale perturbations in temperature and wind of a few degree Kelvin or $\mathrm{m} / \mathrm{s}$, respectively, can seriously alter the sound propagation. Therefore, the climatologies also take into account daily and hourly variations (not shown here). The exact date and daytime is a significant input to the HARPA/DLR-modelling.

\subsection{Quantification of infrasound temperature fluctuations}

A subsequent aspect of propagation modelling is the calculation of singular temperature effects due to the passage of an infrasonic signal through the atmosphere. The temperature perturbation $T^{\prime}$ (see Eq. 1) depends primarily on the particle velocity $u$. Various processes increase and decrease this particle velocity such as geometric spreading loss, atmospheric attenuation loss and amplification with decreasing air density. They will be further discussed below.

Geometric spreading loss (see e.g. Warfield and Jacobson, 1971) is the weakening of a signal, when it expands with increasing range. There are two different kinds of spreading loss, namely spherical and cylindrical loss. If a sound signal (idealized as point source) expands in all directions, its surface expands like a sphere (or hemisphere, when starting at the surface) and with increasing radius $r$, the surface increases proportional to $r^{2}$ (surface of a sphere: $4 \pi r^{2}$ ). If a sound signal originates from a (idealized infinite) line source, the surface expands like a cylinder and increases proportional to $r$ (surface of a cylinder barrel of constant height $h: 2 \pi r h$ ). In reality, the propagation of acoustic rays (see Sect. 2.1) resembles spherical spreading in the near field of the source and becomes more cylindrical in the far field due to ducting and focusing of rays. The cylindrical spreading is assumed for this study. The intensity of a sound signal corresponds to 
the inverse surface increase, so it is proportional to $1 / r$. The sound intensity $I$ is also proportional to the square of particle velocity $u$ and therefore:

$I \propto u^{2} \propto \frac{1}{r} \Rightarrow u \propto \frac{1}{\sqrt{r}}$

Atmospheric attenuation loss (see e.g. Evans et al., 1972) characterizes the weakening of a signal due to damping processes. These processes are subdivided into classical losses (i.e. losses due to viscosity and thermal conductivity of air), diffusion losses and relaxation losses. The classical processes are the most significant ones for middle and upper atmospheric attenuation. Diffusion only contributes with $0.3 \%$ to the total attenuation of a signal and relaxation dominates only in the lower to middle atmosphere, where the overall attenuation is still very weak. The attenuation is frequencydependent and increases with height. Typical heights, where the loss due to attenuation becomes stronger than the amplification due to decreasing air density (described below) are given in Table 1. The attenuation coefficients for the different attenuation processes can be quantified using HARPA/DLR. The total absorption $A$ in decibels can be calculated over a specified distance of propagation; the loss of sound intensity $I$ and particle velocity $u$ due to attenuation can be expressed by (Pilger and Bittner, 2009):

$I \propto u^{2} \propto 10^{-A / 10} \Rightarrow u \propto 10^{-A / 20}$

Amplification with decreasing air density is a process that increases signal amplitude with height. The exponential decrease of air density with height can be represented by the following scale height relation:

$\rho=\rho_{0} e^{-z / H}$

where $\rho$ is the air density, $\rho_{0}$ the air density at surface level $\left(\sim 1.225 \mathrm{~kg} / \mathrm{m}^{3}\right), z$ the height and $H$ the atmospheric scale height $(\sim 6.8 \mathrm{~km}$ as an approximation for all altitudes from ground to lower thermosphere). The squared particle velocity $u^{2}$ of a sound signal has to increase in the same way as the air density $\rho$ decreases if energy conservation (and therewith constant intensity $I$ ) is assumed:

$I=u^{2} \rho c \Rightarrow u \propto \frac{1}{\sqrt{\rho}}$

Following Eqs. (2), (3), and (5) the particle velocity $u$ is proportional to the inverse square root of distance and pressure and the inverse scaled attenuation over 20. Therefore, if both, the distance and the attenuation increases, the particle velocity decreases. If the pressure decreases, the particle velocity increases. Due to the fact that the background air pressure decreases exponentially with height (Eq. 4), the increase of the square of particle velocity is also exponential and it exceeds the decrease due to the other effects until attenuation becomes dominant. Following Eq. (1), the temperature fluctuation $T^{\prime}$ increases in the same way as the particle velocity $u$.
Table 1. Frequency-dependent height, where the processes of atmospheric attenuation start to dominate compared to the amplification by decreasing of air density.

\begin{tabular}{lcccc}
\hline Signal frequency & $10 \mathrm{~Hz}$ & $1 \mathrm{~Hz}$ & $0.1 \mathrm{~Hz}$ & $0.01 \mathrm{~Hz}$ \\
\hline Height & $76 \mathrm{~km}$ & $102 \mathrm{~km}$ & $130 \mathrm{~km}$ & $160 \mathrm{~km}$ \\
\hline
\end{tabular}

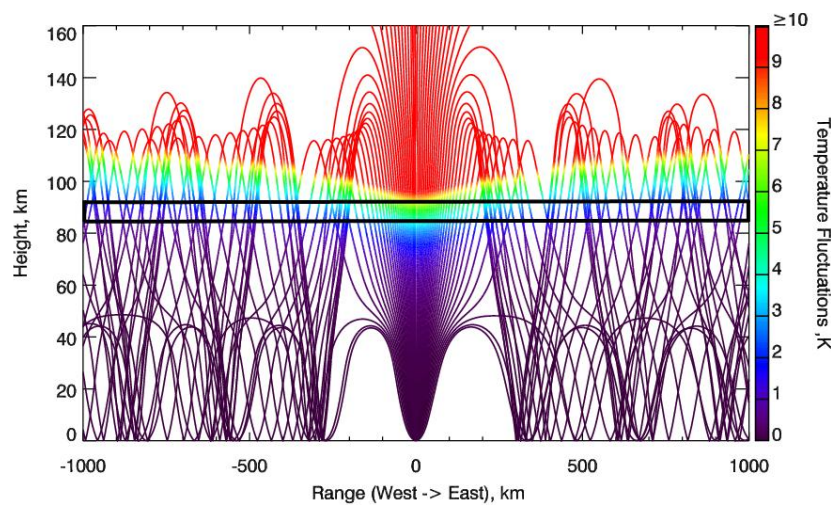

Fig. 6. Temperature fluctuation for a signal of $0.01 \mathrm{~Hz}$ frequency and $100 \mathrm{~Pa}$ pressure amplitude (at $1 \mathrm{~km}$ initial distance from the source) using cylindrical spreading implemented in HARPA/DLR. The $\mathrm{OH}$ layer between 83 and $91 \mathrm{~km}$ is marked by a rectangle.

Figure 6 shows an example of a temperature fluctuation development with height and range. It has been calculated using HARPA/DLR (for more details see Pilger and Bittner, 2009). With increasing height the decreasing air density leads to an exponential increase of the fluctuation. The temperature fluctuations in the $\mathrm{OH}$ layer (ca. $87 \pm 4 \mathrm{~km}$ ) are largest directly above a source. Shown is an example case using strong sound amplitude of $100 \mathrm{~Pa}$ (at $1 \mathrm{~km}$ initial distance from the source) and weak attenuation for a low frequency of $0.01 \mathrm{~Hz}$. The expected temperature fluctuation amounts $\sim 5 \mathrm{~K}$ in the $\mathrm{OH}$ layer for this signal.

\subsection{Infrasound signal identification}

A pattern recognition algorithm is needed in order to reliably identify and classify infrasound signals in the $\mathrm{OH}$ temperature fluctuations originating from different sources. The source characteristics, which can be used to distinguish different signals, are sound frequency, sound amplitude and sound waveform.

While infrasonic frequencies range from $0.003 \mathrm{~Hz}$ to $16 \mathrm{~Hz}$ (corresponding to periods of $5 \mathrm{~min}$ to $0.05 \mathrm{~s}$, see Fig. 1), each source has its own characteristic frequency range. Only a few infrasonic signals have one constant main frequency (e.g. microbaroms: $0.2 \mathrm{~Hz}$ ), while most signal 


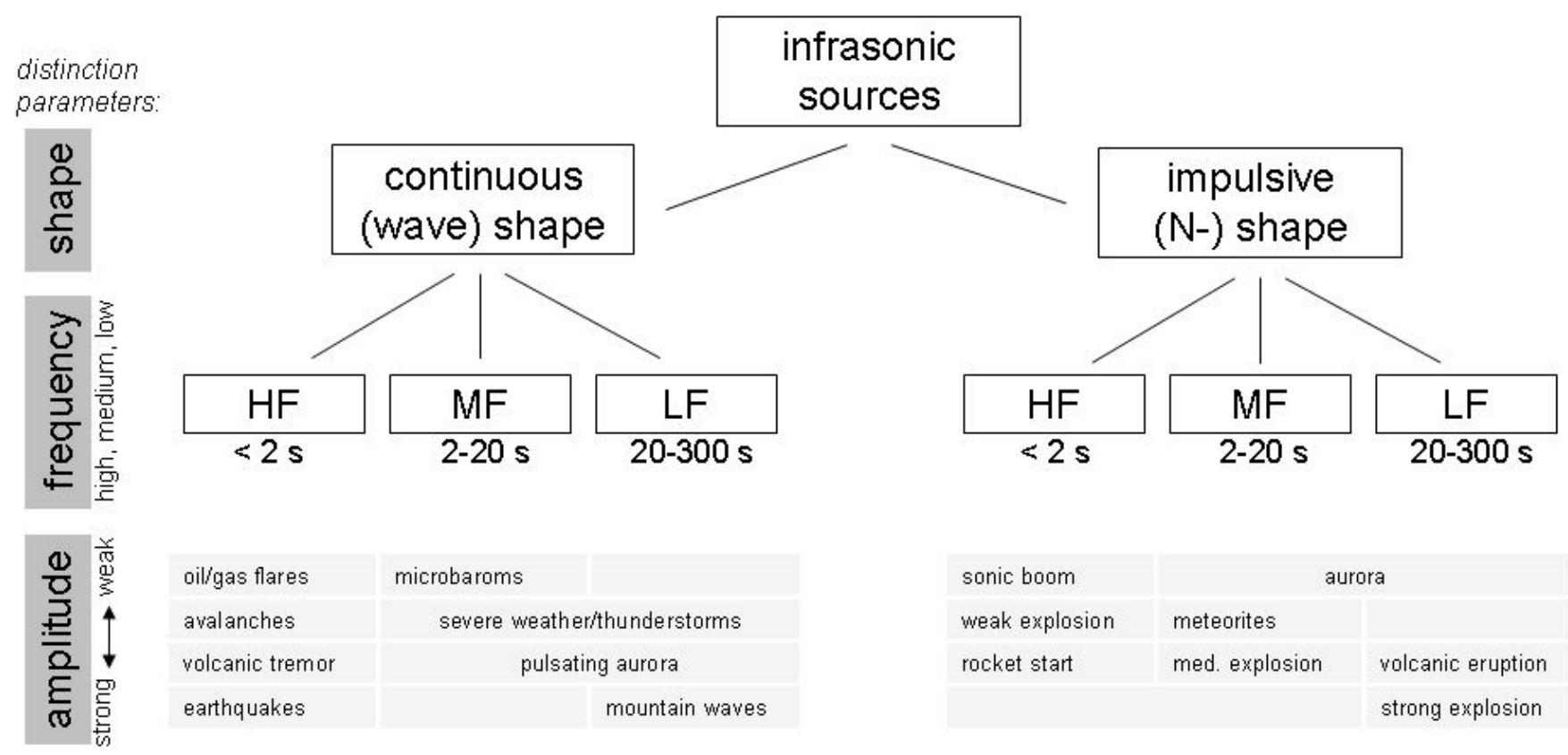

Fig. 7. Distinction scheme for infrasonic sources using the parameters of sound amplitude, frequency and waveform. See text for further details.

frequencies can vary by one or two orders of magnitude. For example, explosion frequencies are yield-dependent: the stronger an explosion, the longer its period. Other prominent long-period ( $>20 \mathrm{~s}$ ) signals are mountain-associated infrasound waves, severe weather and volcanic eruptions, while short-period signals are e.g. due to avalanches, sonic booms and volcanic tremors (see Fig. 7).

A second discrimination parameter in this context is the pressure amplitude of a sound signal. Infrasonic signals vary from nearly undetectable milli-Pascal effects to shockwaves of some hundreds to thousands of Pascal. The most important parameter for amplitude calculations is the distance from the source. This is due to the fact that the sound amplitude predominantly decreases with distance due to geometric spreading loss. This loss is estimated using the above-mentioned ray tracing method (see Sect. 2.1) for the determination of the distance between the signal and its source at a certain time and geometric spreading calculations (see Sect. 2.2) for the quantification of amplitude reduction. As mentioned above, infrasonic signals with weak amplitudes are microbaroms, meteorites, sonic booms and severe weather activities, while stronger signals are due to volcanic, explosive or eruptive activities (see Fig. 7).

A third parameter is the waveform of a sound signal. The discrimination of impulsive signals (with strong peaks or socalled "N-shapes") and continuous signals (with wave-like or alternating characteristics) strongly depends on the instrumental capabilities to detect those waveforms. In a first approach, sonic booms, explosions and eruptions are determined to be impulsive while microbaroms, earthquakes and volcanic activity are continuous (see Fig. 7).
Figure 7 shows a distinction scheme for several of the most common infrasound sources by the parameters frequency, amplitude and waveform. It reflects the first steps to be performed in signal classification and discrimination. Two selected events regarding different infrasound sources are discussed in Sect. 4. Further investigations concerning pattern recognition of infrasonic signals are beyond the scope of this paper.

\section{Measurement technique and instrumentation}

The hydroxyl $(\mathrm{OH})$ airglow originates from a thin layer of about $8 \mathrm{~km}$ thickness at a peak altitude of about $87 \mathrm{~km}$ (e.g. Baker and Stair, 1988). The $\mathrm{OH}$ molecules are formed in an exothermic reaction of ozone with atomic hydrogen (Bates and Nicolet, 1950):

$\mathrm{H}+\mathrm{O}_{3} \rightarrow \mathrm{OH}^{*}\left(v^{\prime} \leq 9\right)+\mathrm{O}_{2}(+3.32 \mathrm{eV})$

During the formation of the products $\mathrm{OH}$ and $\mathrm{O}_{2}$, the chemical excess energy is almost completely converted into vibrational-rotational excitations of the $\mathrm{OH}$ molecule (e.g. Dalgarno, 1963). Subsequently, the $\mathrm{OH}$ molecule regains its energetic ground state by emission of electromagnetic radiation in the visible and near infrared spectrum. The GRIPS instrument measures the $\mathrm{OH}(3-1)$-transition associated with the emission of infrared radiation between $1.5 \mu \mathrm{m}$ and $1.55 \mu \mathrm{m}$ wavelength (see Fig. 8). Using such low energy transitions for the derivation of rotational temperatures avoids non-local-thermodynamic equilibrium problems (e.g. Pendleton et al., 1993). Therefore it is assumed that these rotational temperatures correspond well to the kinetic temperature of the atmosphere. 


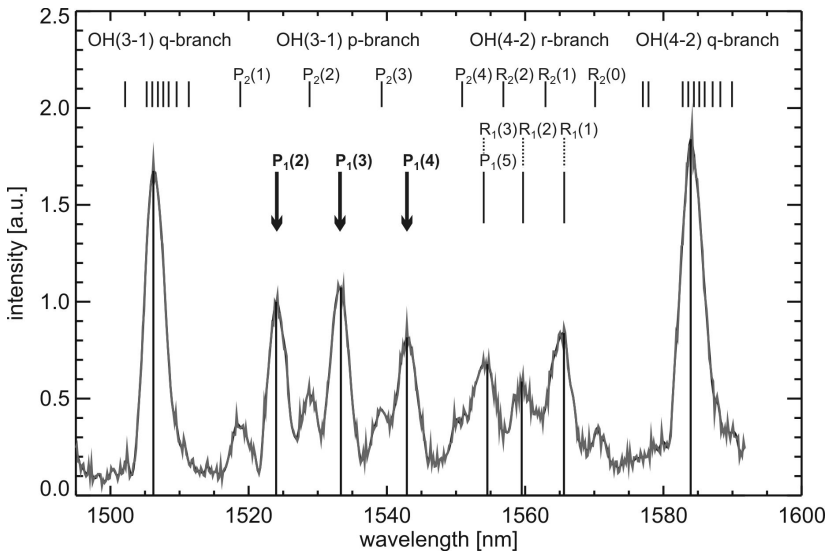

Fig. 8. OH nightglow emissions between $1.5 \mu \mathrm{m}$ and $1.6 \mu \mathrm{m}$ measured with the advanced GRIPS 5 spectrometer. Rotational temperatures are derived from the three strongest lines of the $\mathrm{OH}(3-1)$ p-branch: $\mathrm{P}_{1}(2), \mathrm{P}_{1}(3), \mathrm{P}_{1}(4)$.

The relationship between the intensity of the emission lines $I$ and the corresponding rotational temperature $T_{\text {rot }}$ is given by Meinel (1950b):

$I_{\left(v^{\prime}, J^{\prime}, i \rightarrow v^{\prime \prime}, J^{\prime \prime}, i\right)}=N_{v^{\prime}} \cdot A_{\left(v^{\prime}, J^{\prime}, i \rightarrow v^{\prime \prime}, J^{\prime \prime}, i\right)}$

$\cdot \frac{2\left(2 J^{\prime}+1\right)}{Q_{v^{\prime}, T_{\text {rot }}}} \cdot \exp \left(\frac{-F_{v^{\prime}, J^{\prime}, i}}{k_{\mathrm{B}} T_{\text {rot }}}\right)$

where $N_{v^{\prime}}$ and $Q_{v^{\prime}, T_{\text {rot }}}$ denote the population number and the state sum of the initial vibrational state $v^{\prime}$. A and $F_{v^{\prime}, J^{\prime}, i}$ denote the Einstein coefficient of spontaneous emission and the term value of the rotational level with respect to the vibrational level $v^{\prime}$ and the doublet branch $i$. $J^{\prime}$ is the quantum number of angular momentum and $k_{\mathrm{B}}$ the Boltzmann constant. The temperature retrieval is based on the transition coefficients from Mies (1974) and the rotational energy values from Krassovsky (1962).

The GRIPS spectrometers have been deployed for the observation of $\mathrm{OH}$ airglow for nearly 30 years (see e.g. Bittner et al., 2002; Höppner and Bittner, 2007). The first instruments were designed and built during the early 1980s at the University of Wuppertal, Germany $\left(51.3^{\circ} \mathrm{N}, 7.2^{\circ} \mathrm{E}\right)$. More than two decades of experience and data have been gathered with this instrument series making it a prominent instrument in the history of airglow spectroscopy. At the end of this development line, GRIPS 6 - installed at DLR-DFD in Oberpfaffenhofen, Germany $\left(48.1^{\circ} \mathrm{N}, 11.3^{\circ} \mathrm{E}\right)$ in 2009 - and the identically equipped GRIPS 5 - located at the Environmental Research Station Schneefernerhaus at Mt. Zugspitze, Germany $\left(47.4^{\circ} \mathrm{N}, 11.0^{\circ} \mathrm{E}\right)$ - represent advanced scanning spectrometers for near infrared airglow observations. Both instruments routinely and automatically measure the $\mathrm{OH}$ temperatures night by night (data are available from the World Data Center for Remote Sensing of the Atmosphere, WDC-RSAT, and can be accessed via http://wdc.dlr.de/ndmc).
Originally, the GRIPS system is used to monitor climate signals and observe long-term trends in the mesopause region (e.g. Bittner et al., 2000; Höppner and Bittner, 2007), to better understand the impact of atmospheric dynamics on larger-scale circulation, to validate satellite-based measurements and to evaluate climate and atmospheric models. In addition, high temporal resolution data obtained with the new spectrometers GRIPS 5/6 reveal temperature oscillations with periods below the Brunt-Väisälä period.

Key features of these spectrometers are a thermoelectrically cooled 512 pixel InGaAs-array and a high aperture polychromator. This new spectrometer design offers a temporal resolution of $15 \mathrm{~s}$, well within the infrasound regime (see Fig. 1). The overall dimension of the system is comparatively small with only $600 \times 500 \times 400 \mathrm{~mm}^{3}$ (see Fig. 9). The field of view of GRIPS $5 / 6$ is $7.9^{\circ} \times 7.9^{\circ}$. While the GRIPS 6 is looking into zenith direction, the GRIPS 5 instrument is looking at a zenith angle of $45^{\circ}$ into southward direction, so its field of view is located over Northern Italy (see Fig. 12).

In order to gain reliable estimates of the uncertainty of the derived temperature values, the signal-to-noise ratio of each individual spectrum is derived by applying a low pass filter. The filtered spectrum gives a reliable estimate of the peak intensities, while the residuals are taken as their respective uncertainties. This approach has proven to yield feasible results in gaining the instrument's precision. A convenient side effect of this approach is the fact that precision increases on longer time scales. As a consequence the uncertainty is typically of the order of $7.5 \mathrm{~K}$ for a $15 \mathrm{~s}$ exposure, while decreasing to values below $2 \mathrm{~K}$ at time scales of $1 \mathrm{~min}$. Since the signal-to-noise ratio is a function of source intensity, atmospheric opacity and all possible influences caused by the instrument, the uncertainty of the derived temperatures strongly depends on the measurement conditions. During the nights discussed in Sect. 4, temperature values range from $200 \mathrm{~K}$ to $240 \mathrm{~K}$ for the night of 2 to 3 November 2008 and from $180 \mathrm{~K}$ to $220 \mathrm{~K}$ for 5 to 6 November 2008 , while the respective uncertainties of the $15 \mathrm{~s}$ values range between $7 \mathrm{~K}$ and $12 \mathrm{~K}$ for both nights (see Figs. 10, 11, 13, and 14). Thus the precision of the GRIPS instrument cannot explain the variability in our data and atmospheric waves are the likely explanation as is further confirmed by the results of the wavelet analysis.

\section{Results and discussion}

A field campaign SCARAMANGA ${ }^{1}$ at the Environmental Research Station Schneefernerhaus in the German Alps (UFS, $47.4^{\circ} \mathrm{N}, 11.0^{\circ} \mathrm{E}$ ) was conducted during OctoberDecember 2008. The GRIPS 5 spectrometer was deployed for this campaign to demonstrate the capability of this instrumentation to detect low frequency infrasonic signals.

\footnotetext{
${ }^{1}$ Search for Characteristic Airglow Response to Autumnal Meteoroid Activity during Nocturnal Gauging of the Atmosphere
} 


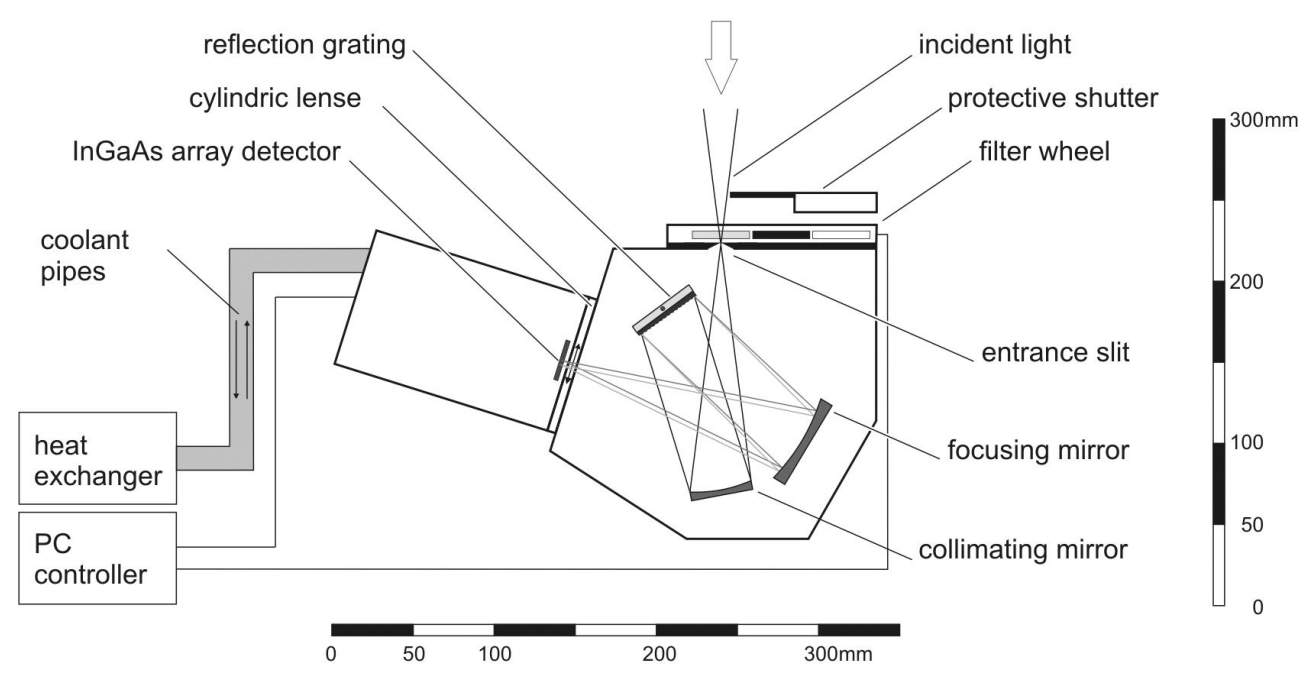

Fig. 9. Side view of the advanced GRIPS spectrometer.

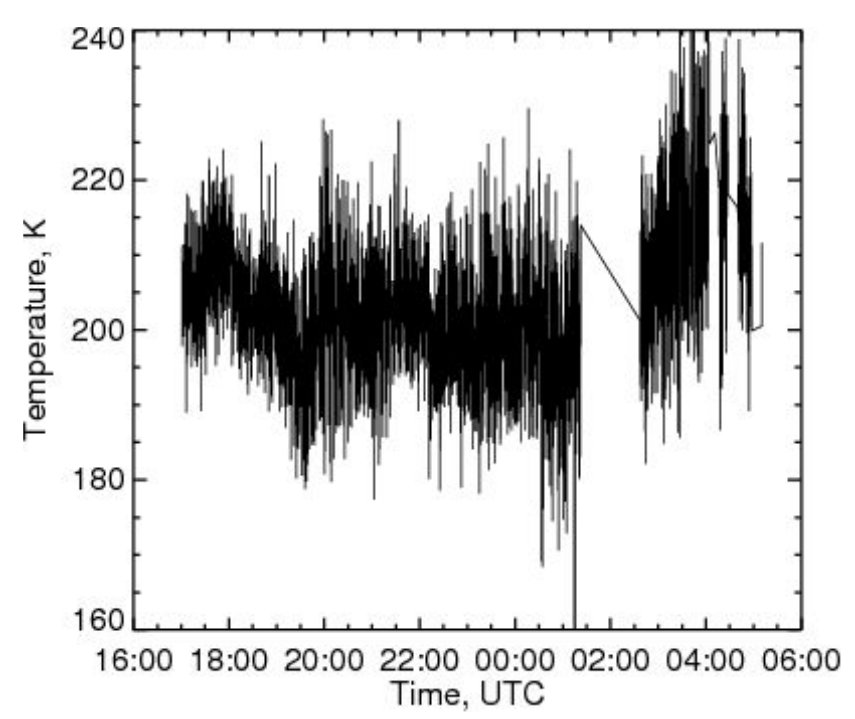

Fig. 10. Nocturnal evolution of $\mathrm{OH}$ temperatures recorded during the night from 5 to 6 November 2008 at the Environmental Research Station Schneefernerhaus $\left(47.4^{\circ} \mathrm{N}, 11.0^{\circ} \mathrm{E}\right)$, Germany. 2466 spectra have been recorded by the GRIPS 5 spectrometer with a temporal resolution of $15 \mathrm{~s}$.

During this campaign, 27 nighttime time series of up to $3000 \mathrm{OH}$ spectra per night were recorded with a maximum temporal resolution of $15 \mathrm{~s}$ per spectrum. In order to check for shorter period fluctuations in the $\mathrm{OH}$-temperature time series we performed a wavelet analysis. Wavelet analysis has proven to yield good results in atmospheric studies, especially if spectral signatures are transient (e.g. Wüst and Bittner, 2006; Höppner and Bittner, 2007; Bittner et al., 1998; Widdel et al., 1994). The wavelet analysis used in this study is based on the algorithm presented by Torrence and Compo (1998). Analyses using the Morlet wavelet function

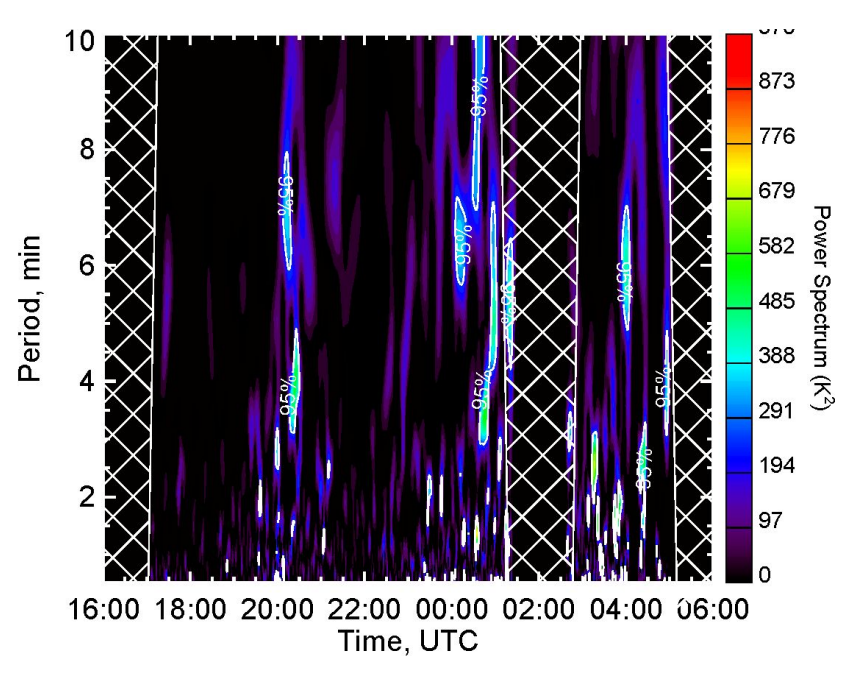

Fig. 11. Wavelet spectrogram based on $\mathrm{OH}$ temperature time series in Fig. 10 in the period range of 0.5 to $10 \mathrm{~min}$. Colours indicate the wavelet power spectrum and white lines denote the $95 \%$ significance level. Hatched areas are excluded due to edge effects of the wavelet analysis. A noticeable amount of wave activity is located around 20:00 UTC, 00:30 UTC and 04:00 UTC.

were performed on the data set in the period range of $0.5-$ $10 \mathrm{~min}$ (for long-period infrasound and short-period gravity wave detection) and in the $0.5-5 \mathrm{~min}$ period range (for pure infrasound detection). 95\% statistically significant areas (spectral peaks in the wavelet spectrum are at this level significantly above a background spectrum as e.g. the spectrum of white noise) in the $\mathrm{OH}$ temperature records provide evidence for sources in the above mentioned period range. We therefore believe that the wavelet analysis used allows estimating the spectral content of the underlying data series and allows detecting infrasonic signals. 
Convective_available_potential_energy @ surface
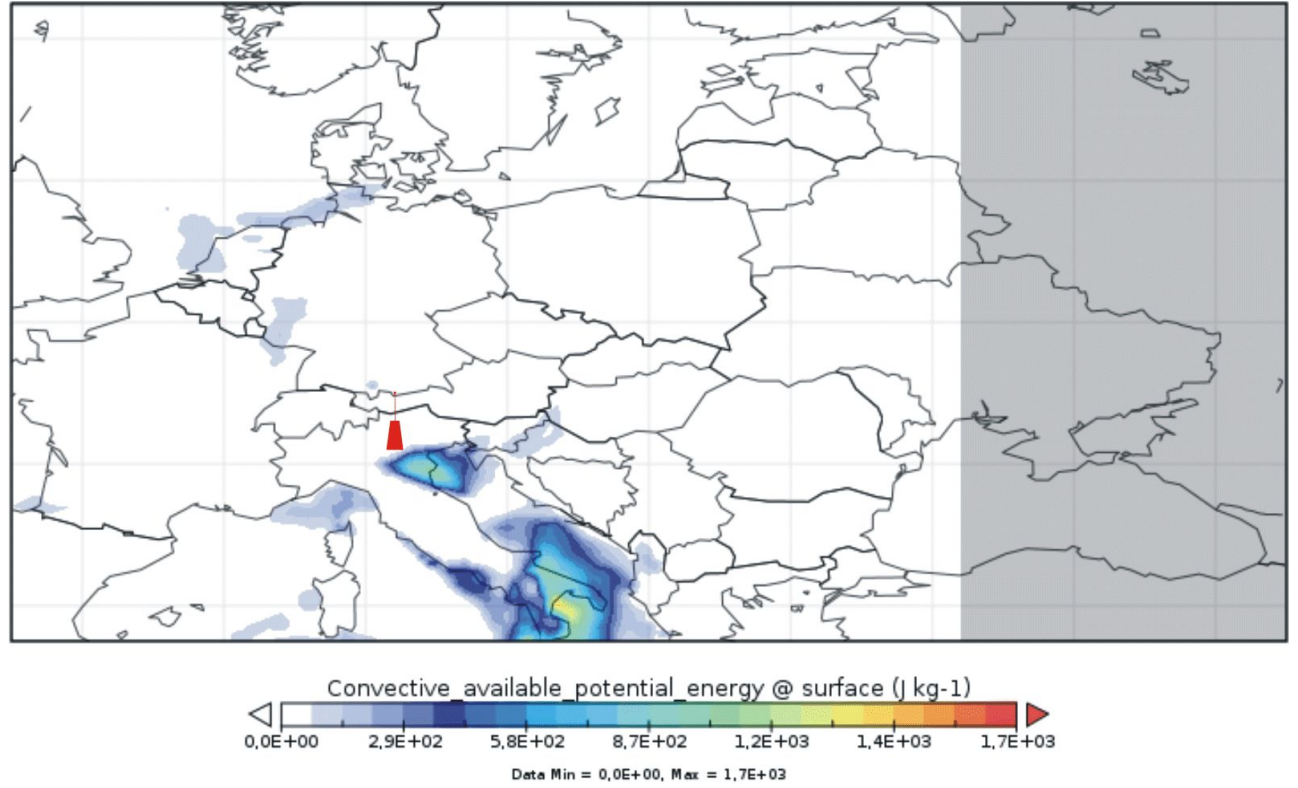

Fig. 12. ECMWF operational analysis of the convective available potential energy (CAPE) at surface level for the 6 November 2008 , 00:00 UTC. Also shown is the location of GRIPS 5 at the Environmental Research Station Schneefernerhaus $\left(47.4^{\circ} \mathrm{N}, 11.0^{\circ} \mathrm{E}\right)($ red circle) and the field of view of the instrument (red trapeze). See text for further details.

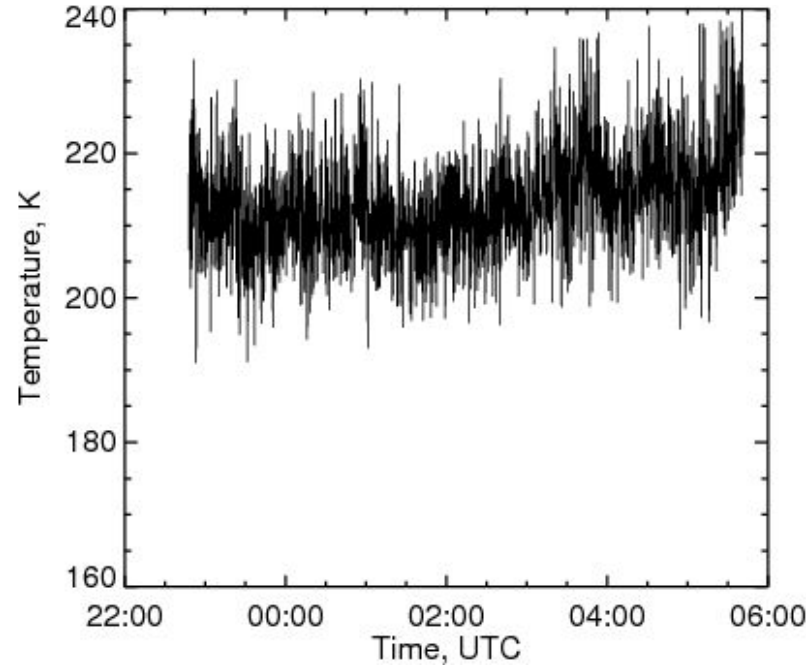

Fig. 13. The same as in Fig. 10, but for the night of 2 to 3 November 2008 from ca. 23:00 UTC to 05:30 UTC based on 1691 spectra.

Figures 10 to 15 show typical examples of nights with significant wave activity in the above mentioned period ranges indicating the impact of short period (infrasonic) signals on mesopause temperature time series.

Figure 10 shows the time series of $\mathrm{OH}(3-1)$ rotational temperatures obtained with the GRIPS 5 instrument during the night of 5 to 6 November 2008. A large data gap between 01:15 UTC and 02:30 UTC is due to dense cloudi-

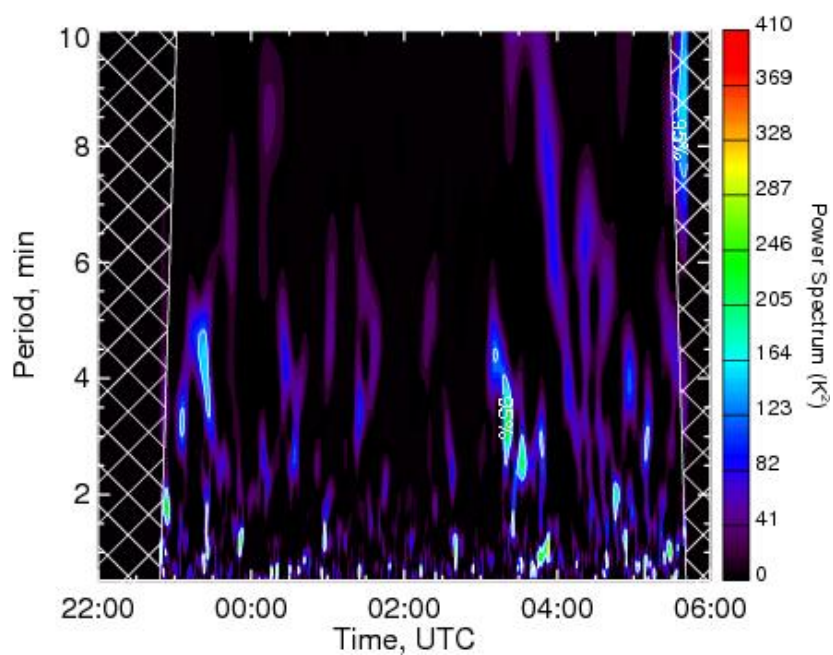

Fig. 14. The same as in Fig. 11, but for the night of 2 to 3 November 2008. A noticeable amount of wave activity is located around 04:00 UTC in a period range of 0.5 to $1.5 \mathrm{~min}$ (see also Fig. 15).

ness within the field of view of the instrument. Nevertheless, a total of 2466 spectra, equivalent to more than $10 \mathrm{~h}$ of observation, were obtained during this night. Figure 11 shows the corresponding wavelet spectrogram of this time series in the period range of 0.5 to $10 \mathrm{~min}$; signals exceeding a $95 \%$ significance level have been identified during the time spans between 19:30 UTC and 21:00 UTC, 23:00 UTC 


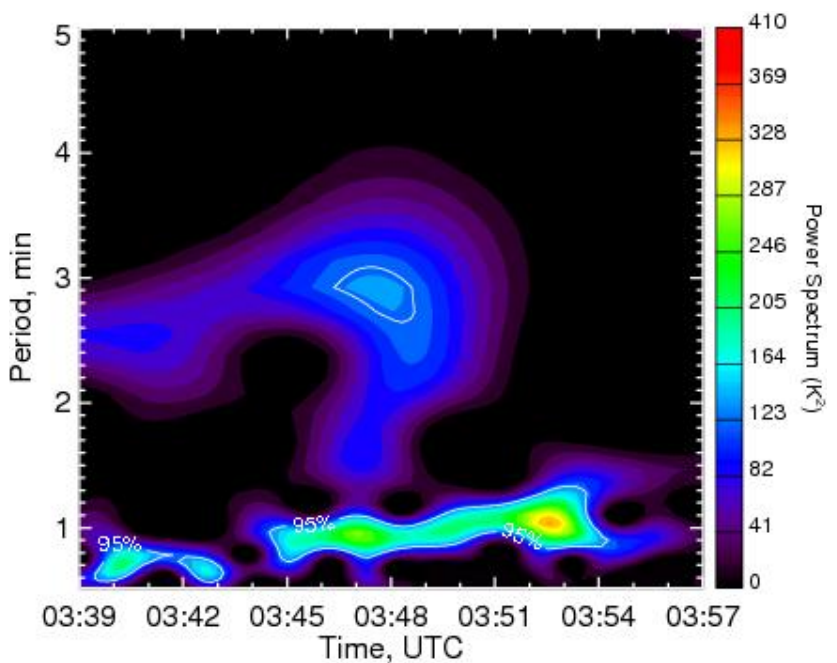

Fig. 15. Detail of Fig. 14 focusing on the measurement time between 03:39 UTC and 03:57 UTC and on periods below $5 \mathrm{~min}$. An area of significant wave activity is located in the 1-min period range lasting about $10 \mathrm{~min}$.

and 01:15 UTC and between 02:30 UTC and 05:00 UTC, respectively. Wave activity is observed in both, the short period gravity wave range with periods around 6 to $8 \mathrm{~min}$ (not discussed here) and the infrasonic period range with periods around 3 to $4 \mathrm{~min}$. We speculate that the latter signatures may be attributed to a meteorological source, due to the fact that $3.5 \mathrm{~min}$ is a typical acoustic period of severe weather (see Georges, 1973; Chimonas and Peltier, 1974; Blanc, 1985). This is indeed in agreement with the fact that some thunderstorm activity was recorded in Northern Italy throughout the whole night. Figure 12 shows the associated convective available potential energy (CAPE) for central Europe quantified by ECMWF operational analysis. A region of increased CAPE and therewith strong thunderstorm potential is centered at about $45^{\circ} \mathrm{N}$ and $12^{\circ} \mathrm{E}$, which is located $300 \mathrm{~km}$ southward of the instrument and approximately $150 \mathrm{~km}$ from the center of the instrument's field of view in the mesopause region. Infrasonic waves generated of the described thunderstorm source reach the field of view in a $150 \mathrm{~km}$ distance as seen in Fig. 6 and could therefore be detected by GRIPS 5 (see Fig. 11).

Figure 13 shows the temperature time series for the second half of the night from 2 to 3 November 2008, based on 1691 spectra in $15 \mathrm{~s}$ intervals. Especially the time frame near 04:00 UTC indicates short period wave activity between 30 and $90 \mathrm{~s}$ over at least $15 \mathrm{~min}$ of continuous duration (see Figs. 14 and 15). Orographical sources are a potential explanation for these signals. The so-called "mountain associated waves (MAWs)" are orographically generated infrasonic waves in a typical period range of 20 to $60 \mathrm{~s} \mathrm{(e.g.} \mathrm{Wil-}$ son and Olson, 2003). These lee waves occur when air is forced over a mountain ridge and is redirected vertically (e.g.
Lyra, 1943). The Alpine region is a well known generator of such orographic waves and we tentatively interpret the signals found as being related to orographical effects. Signals in this period range are frequently observed throughout the campaign data set. The example shown here is a particularly strong event with remarkable continuity.

\section{Conclusions}

Our study demonstrated the potential of the advanced IRspectrometers GRIPS 5/6 for obtaining reliable high resolution spectra allowing the observation of $\mathrm{OH}$ temperature modulations caused by infrasonic waves traveling through the airglow layer.

The GRIPS system utilizes the so-called $\mathrm{OH}$ airglow phenomenon in $80-90 \mathrm{~km}$ altitude. Mesopause temperatures are currently routinely and automatically derived night-by-night from observations of hydroxyl $(\mathrm{OH})$ emissions in the near infrared. The new IR-spectrometers GRIPS 5/6 measuring with a temporal resolution of $15 \mathrm{~s}$ allow the detection of short-period infrasound signals.

An infrasound propagation model was developed (HARPA/DLR) using the existing ray-tracing model HARPA and improving the propagation characteristics by including climatologies for atmospheric background conditions and taking into account the influence of attenuation on a signal. The development of a numerical infrasonic wave pattern recognition algorithm has been initiated.

To demonstrate and test the improved system's performance and the developed modeling approach, a field campaign SCARAMANGA was conducted at the Environmental Research Station Schneefernerhaus $\left(47.4^{\circ} \mathrm{N}, 11.0^{\circ} \mathrm{E}\right)$ from October to December 2008. It was shown that the GRIPS 5/6 instruments are able to measure signals in the period range of low frequency infrasound. The most likely sources of these detected signals are so-called mountain associated infrasound waves generated by the orography of the Alps and meteorological sources such as thunderstorms.

It is concluded, that the measurement system GRIPS 5/6 is in principle suitable for the detection of geo-hazards producing infrasound. The deployment of GRIPS as an additional component in multi-hazard early warning systems could therefore increase the reliability of such systems.

However, further work is needed to set up an operational system for this purpose. The expansion of the measurement system to include the observation of a second airglow layer in an altitude range of $90-100 \mathrm{~km}$ is desirable in order to gather more information about the properties of the observed infrasonic waves. This could be achieved by coupling an $\mathrm{O}_{2}-$ Photometer to the GRIPS instrument. It is also highly desirable for this purpose to expand the existing GRIPS system regarding the capability of measuring airglow during daylight to provide continuous $24 \mathrm{~h}$ surveillance. 
In addition to the instrumental extension, the abovementioned numerical infrasonic wave pattern recognition algorithm has to be further improved to better discriminate superimposed infrasound signatures in the airglow temperature records originating from different sources. Furthermore, the infrasound propagation modeling approach should be coupled with a numerical weather forecast model for a realistic consideration of the background atmospheric conditions instead of relying on climatologies as is currently done.

Finally, a comprehensive testing of the system is needed in the vicinity of different and well characterized infrasound sources.

Acknowledgements. The GITEWS project (German Indonesian Tsunami Early Warning System) is carried out through a large group of scientists and engineers from (GFZ) German Research Centre for Geosciences and its partners from the German Aerospace Center (DLR), the Alfred Wegener Institute for Polar and Marine Research (AWI), the GKSS Research Centre, the Konsortium Deutsche Meeresforschung (KDM), the Leibniz Institute for Marine Sciences (IFM GEOMAR), the United Nations University (UNU), the Federal Institute for Geosciences and Natural Resources (BGR), the German Agency for Technical Cooperation (GTZ), as well as from Indonesian and other international partners. Funding is provided by the German Federal Ministry for Education and Research (BMBF), Grant 03TSU01. We also kindly acknowledge the support of the Environmental Research Station Schneefernerhaus, UFS, (http://www.schneefernerhaus.de) allowing us to perform the SCARAMANGA campaign. We also acknowledge ECMWF for providing the CAPE data. The authors thank the anonymous reviewers for their valuable comments.

Edited by: J. Lauterjung

Reviewed by: two anonymous referees

\section{References}

Baker, D. J. and Stair Jr., A. T.: Rocket measurements of the altitude distributions of the hydroxyl airglow, Phys. Scripta, 37, 611-622, 1988

Bates, D. R. and Nicolet, M.: Atmospheric Hydrogen, Publications of the Astronomical Society of the Pacific, 62(365), 106-110, 1950.

Beig, G., Keckhut, P., Lowe, R. P., Roble, R. G., Mlynczak, M. G., Scheer, J., Fomichev, V. I., Offermann, D., French, W. J. R., Shepherd, M. G., Semenov, A. I., Remsberg, E. E., She, C. Y., Lübken, F. J., Bremer, J., Clemesha, B. R., Stegman, J., Sigernes, F., and Fadnavis, S.: Review of mesospheric temperature trends, Rev. Geophys., 41, 1015-1055, 2003.

Bittner, M., Offermann, D., Graef, H. H., and Donner, M.: Wavelet analysis of upper mesosphere temperature variations, Adv. Space Res., 21, 1445-1448, 1998.

Bittner, M., Offermann, D., and Graef, H. H.: Mesopause temperature variability above a midlatitude station in Europe, J. Geophys. Res., 105, 2045-2058, 2000.

Bittner, M., Offermann, D., Graef, H. H., Donner, M., and Hamilton, K.: An 18-year time series of $\mathrm{OH}$ rotational temperatures and middle atmosphere decadal variations, J. Atmos. Sol.-Terr. Phy., 64, 1147-1166, 2002.

Blanc, E.: Observations in the upper atmosphere of infrasonic waves from natural or artificial sources - A summary, Ann. Geophys., 3, 673-687, 1985, http://www.ann-geophys.net/3/673/1985/.

Bowman, H. S. and Bedard, A. J.: Observations of Infrasound and Subsonic Disturbances Related to Severe Weather, Geophys. J. Int., 26(1-4), 215-242, 1971.

Buriti, R. A., Takahashi, H., Lima, L. M., and Medeiros, A. F. Equatorial planetary waves in the mesosphere observed by airglow periodic oscillations, Adv. Space Res., 35, 2031-2036, 2005.

Campus, P.: The IMS Infrasound Network and its Potential for Detection of Events: Examples of a Variety of Signals recorded Around the World, Inframatics, 06, 13-22, 2004.

Chimonas, G. and Peltier, W. R.: On severe storm acoustic signals observed at ionospheric heights, J. Atmos. Terr. Phy., 36, 821828, 1974.

Dalgarno, A.: Vibrationally excited molecules in atmospheric reactions, Planet. Space Sci., 10, 19-28, 1963.

Drob, D. P., Picone, J. M., and Garcés, M.: Global morphology of infrasound propagation, J. Geophys. Res., 108, 4680-4691, 2003.

Espy, P. J., Stegman, J., and Witt, G.: Interannual variations of the quasi-16-day oscillation in the polar summer mesospheric temperature, J. Geophys. Res., 102, 1983-1990, 1997.

Evans, L. B., Bass, H., and Sutherland, L.: Atmospheric Absorption of Sound: Theoretical Predictions, J. Acoust. Soc. Am., 51, 1565-1575, 1972.

Evers, L. G. and Haak, H. W.: Listening to sounds from an exploding meteor and oceanic waves, Geophys. Res. Lett., 28, 41-44, 2001.

Garcés, M., Caron, P., and Hetzer, C.: Deep Infrasound radiated by the Sumatra Earthquake and Tsunami, EOS T. Am. Geophys. Un., 86(35), 317-320, doi:10.1029/2005EO350002, 2005.

Gavrilov, N. M., Shiokawa, K., and Ogawa, T.: Seasonal variations of medium-scale gravity wave parameters in the lower thermosphere obtained from spectral airglow temperature imager observations at Shigaraki, Japan, J. Geophys. Res., 107, 4755-4764, 2002.

Georges, T. M.: Infrasound from Convective Storms: Examining the Evidence, Rev. Geophys., 11, 571-594, 1973.

Gossard, E. E. and Hooke, W. H.: Waves in the atmosphere: Atmospheric infrasound and gravity waves - Their generation and propagation, Atmospheric Science 2, Elsevier, New York, 1975.

Hedin, A. E., Fleming, E. L., Manson, A. H., Schmidlin, F. J., Avery, S. K., Clark, R. R., Franke, S. J., Fraser, G. J., Tsuda, T., Vial, F., and Vincent, R. A.: Empirical wind model for the upper, middle and lower atmosphere, J. Atmos. Terr. Phys., 58, 14211447, 1996.

Höppner, K. and Bittner, M.: Evidence for Solar signals in the mesopause temperature variability?, J. Atmos. Sol.-Terr. Phys., 69, 431-448, 2007.

Johnson, J. B., Lees, J. M., and Yepes, H.: Volcanic eruptions, lightning, and a waterfall: Differentiating the menagerie of infrasound in the Ecuadorian jungle, Geophys. Res. Lett., 33, 63086311, 2006.

Jones, R. M., Riley, J. P., and Georges, T. M.: HARPA: A versatile 
three-dimensional Hamiltonian ray-tracing program for acoustic waves in the atmosphere above irregular terrain, NOAA Special Report, 1986.

Krasnov, V., Drobzheva, Y., and Lastovicka, J.: Acoustic energy transfer to the upper atmosphere from sinusoidal sources and a role of nonlinear processes, J. Atmos. Sol.-Terr. Phy., 69, 13571365, 2007.

Krassovsky, V. I., Shefov, N. N., and Yarin, V. I.: Atlas of the airglow spectrum 3000-12400 ̊, Planet. Space Sci., 9, 883-915, 1962.

Le Pichon, A., Herry, P., Mialle, P., Vergoz, J., Brachet, N., Garcés, M., Drob, D., and Ceranna, L.: Infrasound associated with 20042005 large Sumatra earthquakes and tsunami, Geophys. Res. Lett., 32, 19802-19806, 2005.

Liszka, L.: Infrasonic Waves - Interaction with the Atmosphere, in: Dynamical and Chemical Coupling Between the Neutral and Ionized Atmosphere, edited by: Grandal, B. and Holtet, J. A., NATO ASIC Proc., 35, 63-71, 1977.

López-González, M. J., Rodríguez, E., García-Comas, M., Costa, V., Shepherd, M. G., Shepherd, G. G., Aushev, V. M., and Sargoytchev, S.: Climatology of planetary wave type oscillations with periods of 2-20 days derived from $\mathrm{O}_{2}$ atmospheric and $\mathrm{OH}(6-2)$ airglow observations at mid-latitude with SATI, Ann. Geophys., 27, 3645-3662, 2009, http://www.ann-geophys.net/27/3645/2009/.

Lyra, G.: Theorie der stationären Leewellenströmung in freier Atmosphäre, ZAMM-Z. Angew. Math. Me., 23(1), 1-28, 1943.

Meinel, A. B.: OH emission bands in the spectrum of the night sky. Part IAstrophys. J., 111, 555-564, 1950a.

Meinel, A. B.: OH emission bands in the spectrum of the night sky. Part II, Astrophys. J., 112, 120-130, 1950b.

Mies, F. H.: Calculated vibrational transition probabilities of $\mathrm{OH}\left(\mathrm{X}^{2} \Pi\right)$, J. Mol. Spectrosc., 53, 150-188, 1974.

Mutschlecner, J. P. and Whitacker, R. W.: Infrasound from earthquakes, J. Geophys. Res., 110, 1108-1118, 2005.

Pendleton, W. R., Espy, P. J., and Hammond, M. R.: Evidence for non-local-thermodynamic-equilibrium rotation in the $\mathrm{OH}$ nightglow, J. Geophys. Res., 98, 11567-11579, 1993.

Picone, J. M., Hedin, A. E., Drob, D. P., and Aikin, A. C.: NRLMSISE-00 empirical model of the atmosphere: Statistical comparisons and scientific issues, J. Geophys. Res., 107, 14681483, 2002.

Pilger, C. and Bittner, M.: Infrasound from tropospheric sources: Impact on mesopause temperature?, J. Atmos. Sol.-Terr. Phy., 71, 816-822, 2009.
PrepCom: Comprehensive Nuclear Test Ban Treaty. Preparatory Commission for the Comprehensive Nuclear Test Ban Treaty Organization, Vienna, 1997.

Reisin, E. R. and Scheer, J.: Gravity wave activity in the mesopause region from airglow measurements at El Leoncito, J. Atmos. Sol.-Terr. Phy., 66, 655-661, 2004.

Ripepe, M. and Marchetti, E.: Array tracking of infrasonic sources at Stromboli volcano, Geophys. Res. Lett., 29(22), 2076-2079, 2002.

Rudloff, A., Lauterjung, J., Münch, U., and Tinti, S.: Preface "The GITEWS Project (German-Indonesian Tsunami Early Warning System)", Nat. Hazards Earth Syst. Sci., 9, 1381-1382, doi:10.5194/nhess-9-1381-2009, 2009.

Schubert, G., Hickey, M. P., and Walterscheid, R. L.: Physical processes in acoustic wave heating of the thermosphere, J. Geophys. Res., 110, 7106-7110, 2005.

Sivjee, G. G., Walterscheid, R. L., and McEwen, D. J.: Planetary wave disturbances in the Artic winter mesopause over Eureka $\left(80^{\circ} \mathrm{N}\right)$, Planet. Space Sci. 42, 973-986, 1994.

Sutherland, L. C. and Bass, H. E.: Atmospheric absorption in the atmosphere up to $160 \mathrm{~km}$, J. Acoust. Soc. Am., 115, 1012-1032, 2004.

Takahashi, H., Buriti, R. A., Gobbi, D., and Batista, P. P.: Equatorial planetary wave signatures observed in mesospheric airglow emissions, J. Atmos. Sol.-Terr. Phy., 64, 1263-1272, 2002.

Torrence, C. and Compo, G. P.: A Practical Guide to Wavelet Analysis, B. Am. Meteorol. Soc., 79, 61-78, 1998.

Warfield, J. T. and Jacobson, M. J.: Invariance of geometric spreading loss with changes in ray parametrization, J. Acoust. Soc. Am., 50(1), 342-347, 1971.

Widdel, H., Bittner, M., and Hoppe, U.: Vertical velocities measured at Biscarrosse and by EISCAT at Tromso during the DYANA campaign, J. Atmos. Terr. Phys., 56, 1779-1796, 1994.

Wilson, C. R. and Olson, J. V.: Mountain Associated Waves at I53US and I55US in Alaska and Antarctica in the Frequency Passband from 0.015 to $0.10 \mathrm{~Hz}$, Inframatics, 3, 6-10, 2003.

Wüst, S. and Bittner, M.: Non-linear resonant wave-wave interaction (triad). Case studies based on rocket data and first application to satellite data, J. Atmos. Sol.-Terr. Phy., 68, 969-976, 2006. 